\title{
Diagnostic Performance of Radial Probe Endobronchial Ultrasound without a Guide- Sheath and the Feasibility of Molecular Analysis
}

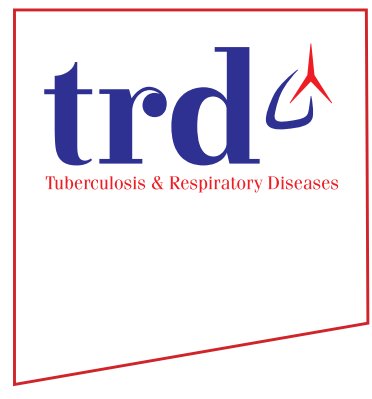

\author{
Seong Mi Moon, M.D. (i), Junsu Choe, M.D., Byeong-Ho Jeong, M.D., Ph.D., Sang-Won Um, M.D., \\ Ph.D., Hojoong Kim, M.D., Ph.D., O Jung Kwon, M.D., Ph.D. and Kyungjong Lee, M.D. \\ Division of Pulmonary and Critical Care Medicine, Department of Medicine, Samsung Medical Center, Sungkyunkwan \\ University School of Medicine, Seoul, Korea
}

Background: Radial probe endobronchial ultrasound (R-EBUS), is effective for tissue diagnosis of lung lesions. We evaluated the diagnostic performance of R-EBUS both a guide-sheath and fluoroscopy and identified factors associated with accurate diagnosis. The feasibility of molecular and genetic testing, using specimens obtained by R-EBUS, was also investigated.

Methods: The study retrospectively reviewed 211 patients undergoing R-EBUS without a guide-sheath and fluoroscopy, June 2016-May 2017. After excluding 27 patients of which the target lesion was not reached, 184 were finally included. Multivariate logistic regression was used, to identify factors associated with accurate diagnosis.

Results: Among 184 patients, R-EBUS-guided biopsy diagnosed malignancy in 109 patients (59\%). The remaining 75 patients (41\%) with non-malignant results underwent additional work-ups, and 34 were diagnosed with malignancy. Based on final diagnosis, diagnostic accuracy was 80\% (136/170), and sensitivity and specificity for malignancy were $76 \%$ (109/143) and 100\% (27/27), respectively. In multivariate analysis, peripheral location (adjusted odds ratio [aOR], 3.925; 95\% confidence interval [CI], 1.203-12.811; $\mathrm{p}=0.023$ ), and central position of the probe (aOR, 2.435; 95\% CI, 1.424-7.013; $\mathrm{p}=0.035$ ), were associated with accurate diagnosis of malignancy. Molecular and genetic analyses were successful, in all but one case, with inadequate specimens.

Conclusion: R-EBUS-guided biopsy without equipment, is effective for tissue diagnosis. Peripheral location and central position of the radial probe, were crucial for accurate diagnosis. Performance of molecular and genetic testing, using samples obtained by R-EBUS, was satisfactory.

Keywords: Diagnosis; Ultrasonography; Ultrasonics; Bronchoscopy; Lung Neoplasms

Address for correspondence: Kyungjong Lee, M.D.

Division of Pulmonary and Critical Care Medicine, Department of Medicine, Samsung Medical Center, Sungkyunkwan University School of Medicine, 81 Irwon-ro, Gangnam-gu, Seoul 06351, Korea

Phone: 82-2-3410-0777, Fax: 82-2-3410-3849, E-mail: kj2011.lee@samsung.com

Received: Oct. 15, 2018, Revised: Apr. 1, 2019, Accepted: May. 2, 2019, Published online: May. 31, 2019

(c) It is identical to the Creative Commons Attribution Non-Commercial License (http://creativecommons.org/licenses/by-nc/4.0/) 


\section{Introduction}

In the era of precision medicine, acquisition of adequate tissue in lung cancer patients is important for a diagnosis ${ }^{1}$. Minimally invasive tissue sampling is warranted for the diagnosis and molecular testing in these patients in order to decrease the complication and manage the lung cancer ${ }^{2}$. Because conventional bronchoscopy can produce a suboptimal diagnostic yield for tissue sampling in peripheral lung lesion ${ }^{3}$, promising new modalities include radial probe endobronchial ultrasound (R-EBUS), electromagnetic navigation bronchoscopy (ENB), and virtual bronchoscopy $(\mathrm{VB})^{4-7}$ are being introduced in the clinical practice.

R-EBUS is a long, thin ultrasound probe with a $360^{\circ}$ view of the surrounding lung ${ }^{8}$ that can be used with or without additional equipment, such as a guide-sheath (GS) and fluoroscopy. The reported diagnostic yield of R-EBUS-guided biopsy varies with the procedure type ${ }^{9,10}$. GS with fluoroscopy is commonly used in combination with radial ultrasound to maintain the probe in the target lesion and optimize the transbronchial lung biopsy (TBLB) because TBLB cannot be performed under real time guidance. Although it can improve the diagnostic yields of peripheral lung nodules, this has also several drawbacks related with a risk of radiation exposure and additional cost of the GS. In addition, R-EBUS-guided TBLB should be performed using small sized forcep to pass the GS, which may obtain inadequate tissue for molecular and genetic analysis. Due to these limitations, transbronchial biopsy using radial ultrasound without additional equipment may be performed with a method of direct distance measure ${ }^{11-13}$. Regarding this method, diverse factors may affect the accuracy of diagnosis and appropriate selection of the patient is important to success the diagnosis of lung nodule $\mathrm{e}^{12,14}$.

In this study, we evaluated the diagnostic performance of $\mathrm{R}$ EBUS without both a GS and fluoroscopy and identified the factors associated with an accurate diagnosis of malignancy. The feasibility of molecular and genetic testing using the REBUS biopsy was also investigated.

\section{Materials and Methods}

\section{Study population}

In our institution, R-EBUS was introduced in January 2016. The first 5 months were considered as learning period and 22 cases of procedures in the period were not included in this study. This study retrospectively reviewed 211 consecutive patients who underwent R-EBUS-guided TBLB from June 2016 to May 2017 for diagnosing lesions difficult to reach using flexible bronchoscopy. After excluding 27 patients (13\%) in whom the probe failed to reach the target lesions, this study enrolled 184 patients (87\%) with biopsy specimens that were obtained using R-EBUS.

\section{Procedure and equipment}

Before R-EBUS-guided TBLB, bronchoscopic evaluation was performed under conscious sedation induced with midazolam and fentanyl to evaluate tracheobronchial tree. A 4-mm bronchoscope (BF P260F; Olympus, Tokyo, Japan) was used to reach the sub-subsegmental level nearest to the suspected tumor after reviewing computed tomography (CT) or positron emission tomography-CT images. Then, the R-EBUS probe (1.4-mm, 20-MHz, UM S20-17S; Olympus) was inserted through the bronchoscope working channel. When the target was found on ultrasound, the length of the probe inserted between the tip of the R-EBUS and outer level of the working channel was measured. After the probe was removed, a 1.8$\mathrm{mm}$ biopsy forceps was marked at the same length using tape and inserted through the working channel for TBLB. No GS or fluoroscopy was used.

\section{Definitions of characteristics on CT and ultrasound}

The location of the lesions on CT was classified as "central" (inner one-third of the hemithorax) or "peripheral" (outer twothirds of the hemithorax). The bronchus sign on CT was categorized as "central", "adjacent", or "invisible"15. In the "central" type, the nearest bronchus clearly reached the target lesion, while in the "invisible" type, no bronchus was detected around the lesion; otherwise, it was categorized as "adjacent" (Figure $1 \mathrm{~A})^{15}$.

The ultrasound findings were classified as "within" (the radial probe was within the center of the target lesion and completely surrounded by the lesion) or "adjacent" (the radial probe was adjacent to the target lesion and not completely in contact with the lesion) (Figure 1B) ${ }^{12}$.

\section{Definition of diagnostic classification}

Based on the biopsy obtained by R-EBUS, the result was primarily classified as malignant or non-malignant. A malignant diagnosis was a primary or metastatic cancer on R-EBUSguided biopsy and was designated as true-positive. Nonmalignant result included a few atypical cells, granuloma, and non-specific inflammation; these underwent further evaluation to obtain a final diagnosis and the patients finally diagnosed with malignancy were considered false-negative. Benign disease was considered true-negative and included infectious disease caused by a specific etiology, organizing pneumonia with focal lesion, and lesions that markedly improved in follow-up images and were judged as benign by the attending physician. In cases with non-malignant results not diagnosed with specific benign disease, if cases did not show definite size decrease during follow-up or were lost to follow- 
A

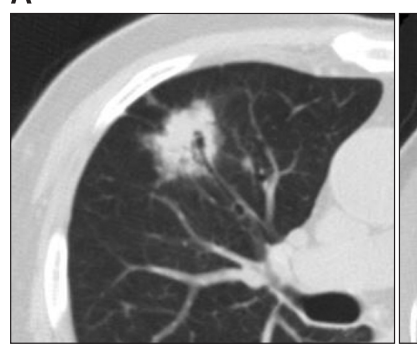

Central

B

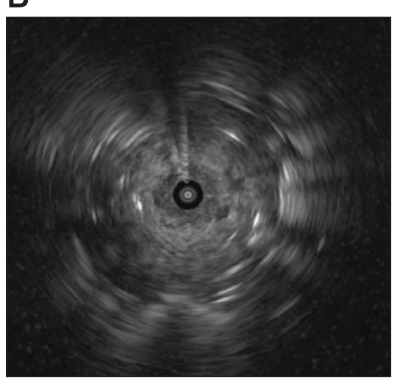

Within

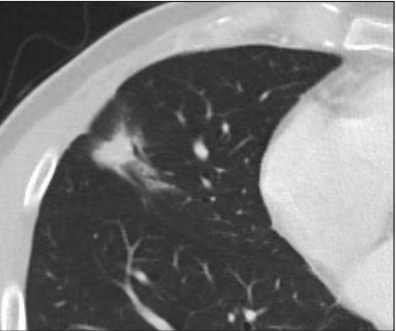

Adjacent

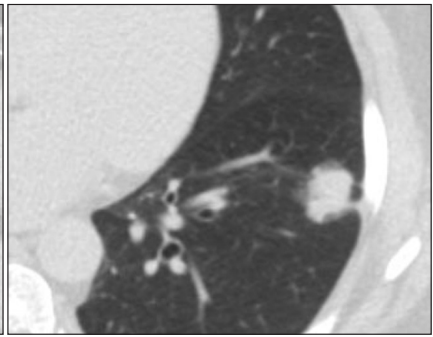

Invisible

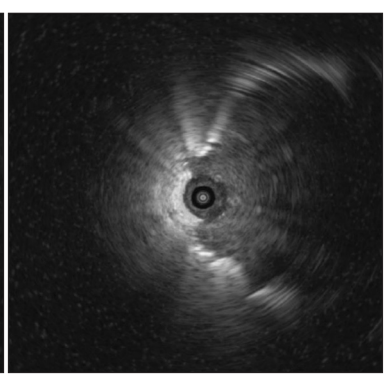

Adjacent

Figure 1. (A) Bronchus sign on computed tomography. They were categorized into three types. "Central" type was defined as the nearest bronchus, clearly reached the target lesion and "invisible" type was defined as no bronchus, was detected around the lesion and otherwise, was categorized as "adjacent." (B) Bronchus sign on ultrasound. They were categorized into two types. The radial probe within the center of the target lesion, and completely surrounded by the lesion was classified as "within". The radial probe adjacent to the target lesion, and not completely in contact with the lesion, was defined as "adjacent."

up, the final diagnosis remained unknown.

\section{Results}

\section{Statistical analysis}

Continuous variables are presented as medians (interquartile range $[\mathrm{IQR}]$ ) and categorical variables as numbers (percentages). To estimate diagnostic performance, the sensitivity for a malignant result, specificity, and positive and negative predictive values of the R-EBUS procedure were calculated. Diagnostic accuracy was calculated by dividing the number of true-positives and true-negatives by the total number of cases, excluding those with unknown results. To investigate factors affecting the accuracy of diagnosis of malignancy, univariate and multivariate logistic regression with backward selection were performed. A two-sided p-value $<0.05$ was considered significant. All data were analyzed with SPSS software version 24.0 (IBM Corp., Armonk, NY, USA).

\section{Ethics statement}

This study was approved by the Institutional Review Board of Samsung Medical Center (IRB No. 2017-09-058). The requirement for informed consent was waived with respect to the use of medical data, because the patient information was anonymized and de-identified before analysis.

\section{Baseline characteristics}

Table 1 summarizes the baseline characteristics of the patients who underwent biopsy using R-EBUS. Their median age was 65 years (IQR, 58-73 years) and 93 (51\%) were male. Forty-one patients (22\%) had underlying lung disease, including chronic obstructive pulmonary disease, lung fibrosis, and pneumoconiosis. The tumor was smaller than $30 \mathrm{~mm}$ in 89 patients (48\%) and the median size was $32 \mathrm{~mm}$ (IQR, 24-42 $\mathrm{mm})$. The most common tumor location was the right upper lobe $(\mathrm{n}=46,25 \%)$ and the majority $(89 \%)$ were located in the peripheral zone. The lesions were classified as solid (80\%), partly solid (18\%), or ground-glass opacity (2\%) types. The bronchus sign on CT was the central type in 98 (53\%) cases, adjacent type in $73(40 \%)$, and invisible type in $13(7 \%)$. The probe was located within the lesion in $78(42 \%)$ cases and adjacent to the lesion in 106 (58\%) cases.

\section{Initial result and final diagnosis}

Figure 2 shows the initial result and final diagnoses. Of the 184 patients, 109 (59\%) were diagnosed with malignancy by R-EBUS-guided biopsy. In 75 patients (41\%) with nondiagnostic results, further work-ups were performed, including surgical resection $(\mathrm{n}=25,33 \%)$, lymph node biopsy $(\mathrm{n}=3$, $4 \%)$, percutaneous needle biopsy $(\mathrm{n}=5,7 \%)$, follow-up imag$\operatorname{ing}(\mathrm{n}=29,39 \%)$, and culture for respiratory specimens $(\mathrm{n}=9$, $12 \%$ ). Of these 75 patients, 34 (45\%) were diagnosed with ma- 
Table 1. Baseline characteristics

\begin{tabular}{|c|c|}
\hline Characteristic & $\begin{array}{c}\text { Value } \\
(n=184)\end{array}$ \\
\hline Age, yr & $65(58-73)$ \\
\hline Male sex & $93(51)$ \\
\hline \multicolumn{2}{|l|}{ Underlying lung disease } \\
\hline Chronic obstructive pulmonary disease & $34(18)$ \\
\hline Idiopathic pulmonary fibrosis & $3(2)$ \\
\hline Combined pulmonary fibrosis and emphysema & $2(1)$ \\
\hline Pleuroparenchymal fibroelastosis & $1(0.5)$ \\
\hline Pneumoconiosis & $1(0.5)$ \\
\hline Size, $\mathrm{mm}$ & $32(24-42)$ \\
\hline$\leq 30$ & $89(48)$ \\
\hline$>30$ & $95(52)$ \\
\hline \multicolumn{2}{|l|}{ Lesion location } \\
\hline Right upper lobe & $46(25)$ \\
\hline Right middle lobe & $20(11)$ \\
\hline Right lower lobe & $28(15)$ \\
\hline Left upper lobe upper division & $37(20)$ \\
\hline Left upper lobe lingular division & $14(8)$ \\
\hline Left lower lobe & $39(21)$ \\
\hline \multicolumn{2}{|l|}{ Lung zone on CT scan } \\
\hline Central, inner one-third & $20(11)$ \\
\hline Peripheral outer two-third & $164(89)$ \\
\hline \multicolumn{2}{|l|}{ Characteristics } \\
\hline Solid & $147(80)$ \\
\hline Nodular lesion & $117(64)$ \\
\hline Cavitary lesion & $18(10)$ \\
\hline Consolidative lesion & $12(6)$ \\
\hline Part-solid & $33(18)$ \\
\hline Ground-glass opacity & $4(2)$ \\
\hline \multicolumn{2}{|l|}{ Bronchus sign on CT scan } \\
\hline Central & $98(53)$ \\
\hline Adjacent & $73(40)$ \\
\hline Invisible & $13(7)$ \\
\hline \multicolumn{2}{|l|}{ Bronchus sign on US } \\
\hline Within & $78(42)$ \\
\hline Adjacent & $106(58)$ \\
\hline
\end{tabular}

Values are presented as median (interquartile range) or number (\%). CT: computed tomography; US: ultrasonography.

lignancy and the other 27 (36\%) were diagnosed with benign disease including specific infections such as tuberculosis $(\mathrm{n}=6)$ and non-tuberculous mycobacterial infection ( $\mathrm{n}=2)$, aspergil- loma $(\mathrm{n}=1)$, and bacterial infection $(\mathrm{n}=3)$ which showed response to antibiotic treatment and other specific disease such as organizing pneumonia (n=1) and IgG4 related disease (n=1) and the lesions improved in follow-up images were judged to be benign $(n=13)$. However, the final diagnosis remained unknown in 14 patients (19\%) because there were no changes within 2 years on follow-up CT images or lost to follow-up.

Overall, malignancy was diagnosed in 143 of 184 patients (78\%), with 27 true-negatives (15\%) after adequate investigations.

In four cases of ground-glass opacity, R-EBUS-guided biopsy diagnosed one case with adenocarcinoma and the three were non-malignant results. The final diagnosis was three adenocarcinomas and one inflammatory lesion.

\section{Diagnostic performance}

After excluding the 14 patients with unknown diagnoses, the diagnostic performance of R-EBUS in 170 patients was calculated (Table 2). Based on the initial and final outcomes, the accuracy, calculated as the sum of true-positive $(n=109$, $64 \%)$ and true-negative $(\mathrm{n}=27,16 \%)$ divided by the total number $(n=170)$, was $80 \%$. Because of false negatives $(n=34,20 \%)$, the sensitivity and negative predicted value were calculated as $76 \%$ and $44 \%$, respectively.

In the 143 patients who were ultimately diagnosed with malignancy, diagnostic performance was calculated according to each baseline characteristic (Figure 3). The highest diagnostic accuracy was observed when the lesion was in the middle lobes $(85 \%)$ and the radial probe was located within the lesion $(84 \%)$. The lowest diagnostic accuracy was seen when the lesion was located centrally on CT (53\%).

4. Factors for accurate diagnosis with R-EBUS-guided biopsy in patients with malignancy

In patients ultimately diagnosed with malignancy, the factors associated with an accurate diagnosis were investigated (Table 3). Univariate analyses revealed that larger size $(\geq 30$ $\mathrm{mm}$; odds ratio $[\mathrm{OR}], 2.245$; 95\% confidence interval [CI], 1.010-4.987; $\mathrm{p}=0.047$ ), peripheral lesion (OR, 3.273; 95\% CI, 1.090-9.830; $\mathrm{p}=0.035$ ), and an ultrasound finding of the "within" type (OR, 3.160; 95\% CI, 1.424-7.013; p=0.005) were significantly associated with an accurate diagnosis of malignancy. In the multivariate analysis, peripheral location (adjusted OR [aOR], 3.925; 95\% CI, 1.203-12.811; $\mathrm{p}=0.023$ ) and the "within" type (aOR, 2.435; 95\% CI, 1.064-5.572; $\mathrm{p}=0.035$ ) remained independent factors influencing the diagnostic accuracy.

5. Molecular and genetic analyses in malignant cases with R-EBUS-guided biopsy

In some patients diagnosed with malignancy using R-EBUS, 


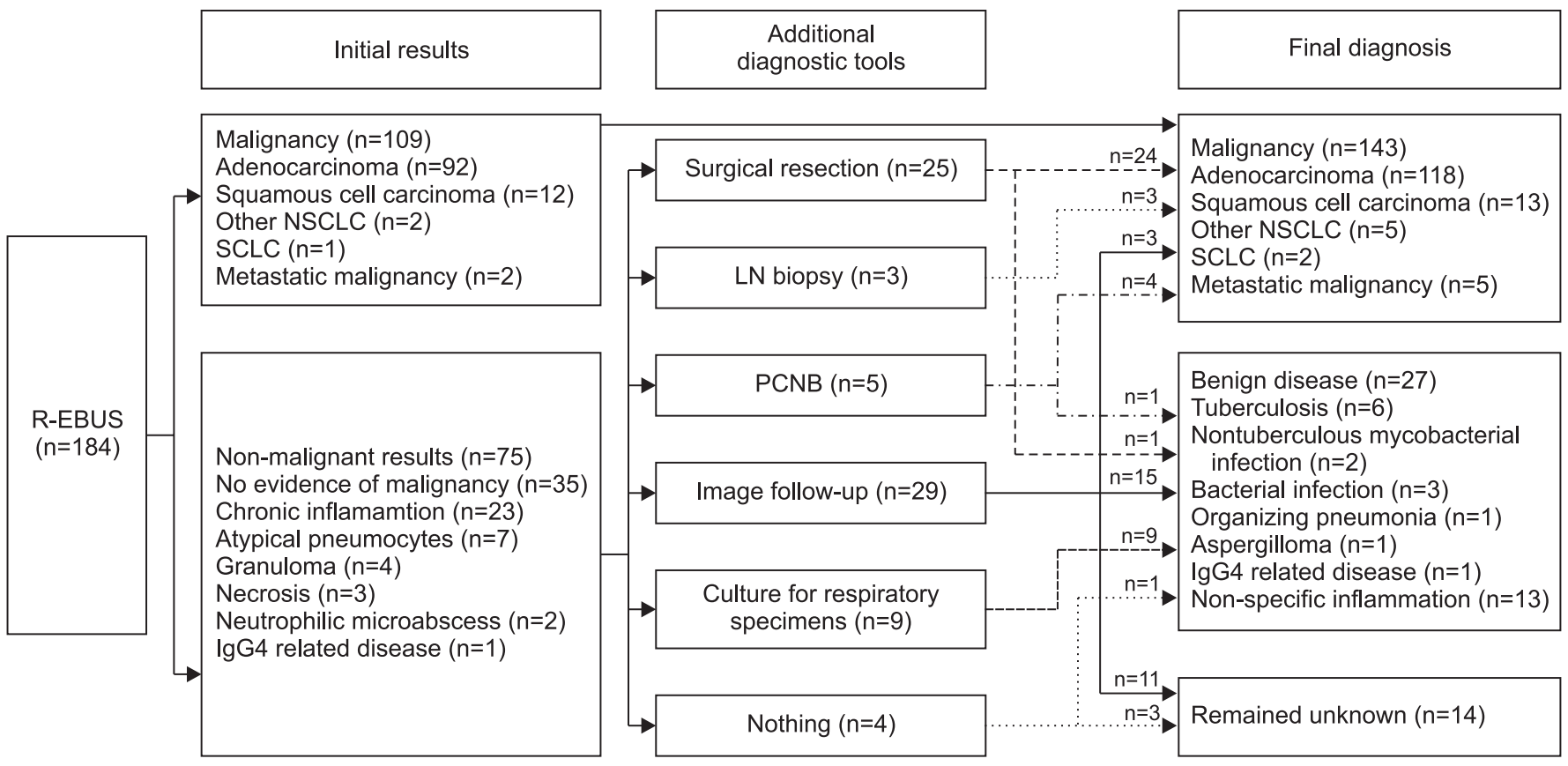

Figure 2. Initial result and final diagnosis. R-EBUS: radial probe endobronchial ultrasound; NSCLC: non-small cell lung cancer; SCLC: small cell lung cancer; LN: lymph node; PCNB: percutaneous needle biopsy.

Table 2. Diagnostic performance of R-EBUS-guided biopsy $(\mathbf{n}=\mathbf{1 7 0})$

\begin{tabular}{|lccc|}
\hline & Final diagnosis: malignant & Final diagnosis: benign & Total \\
\hline R-EBUS result: malignant & 109 (true-positive) & 0 (false-positive) & 109 \\
\hline R-EBUS result: non-malignant & 34 (false-negative) & 27 & \\
\hline Total & 143 & & \\
\hline Accuracy, $\%$ & 80 & & \\
\hline Sensitivity, $\%$ & 76 & \\
\hline Specificity, $\%$ & 100 & \\
\hline Positive predictive value, $\%$ & 100 & \\
\hline Negative predictive value, $\%$ & 44 & \\
\hline
\end{tabular}

Values are presented as number of patients.

* Of 184 patients, 14 patients of which final diagnosis remained unknown, were excluded.

R-EBUS: radial-probe endobronchial ultrasound.

the specimen obtained with the R-EBUS procedure underwent molecular and genetic analysis (Table 4). Of the specimens from 109 patients with malignancy, epidermal growth factor receptor $(E G F R)$ mutation testing was performed in 64 specimens (59\%), and 1 ( $2 \%$ ) failed due to inadequate specimens. The cases with sufficient specimens $(\mathrm{n}=63,98 \%)$ underwent the analysis. A specimen diagnosed as adenocarcinoma underwent EGFR mutation, anaplastic lymphoma kinase (ALK) immunohistochemistry (IHC) and programmed death-ligand 1 (PD-L1) IHC genetic analyses and there were sufficient specimens for EGFR mutation, ALK IHC, and PDL1 IHC testing in $98 \%, 100 \%$, and $94 \%$ of the adenocarcinoma cases, respectively.

\section{Complications}

In a total 184 patients, nine cases of pneumothorax (4.8\%) occurred. Of them, three patients required chest tube insertion and the rest six were improved with conservative care including oxygen supply. Pneumonia occurred in only one case $(0.5 \%)$ treated with oral antibiotics.

\section{Discussion}

This study investigated the diagnostic performance of REBUS without both a GS and fluoroscopy and the diagnostic 


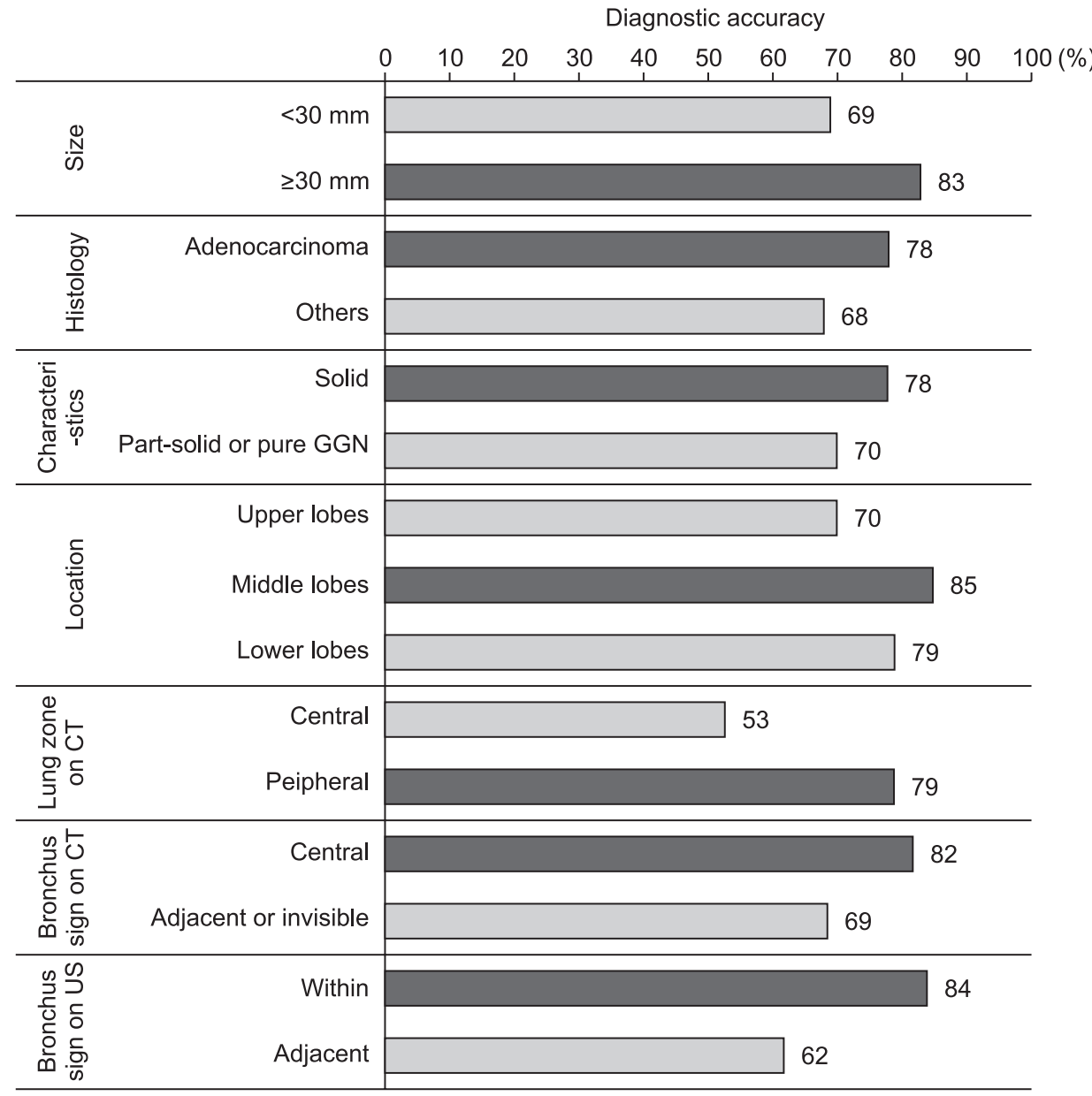

Figure 3. Diagnostic performance of REBUS-guided biopsy, based on clinical characteristics in patients with malignancy $(n=143)$. R-EBUS: radial probe endobronchial ultrasound; GGN: ground glass nodule; CT: computed tomography; US: ultrasonography. accuracy, sensitivity, and negative predictive value were $80 \%$, $76 \%$, and $44 \%$, respectively. The independent factors influencing an accurate diagnosis in R-EBUS-guided biopsy were a peripherally located lesion and the "within" type of bronchus sign on ultrasound. Moreover, molecular and genetic analyses were performed successfully with sufficient material in most $(63 / 64,98 \%)$ cases.

The reported diagnostic performance of R-EBUS ranges from $46 \%$ to $91 \%^{16,17}$ and the overall diagnostic yield in a recent meta-analysis was $71 \%^{9}$. The reason for the variation in diagnostic performance is that the R-EBUS procedure can involve several tools, including a GS ${ }^{14,15,18,19}$, fluoroscopy ${ }^{20}$, or both ${ }^{17,21}$. Although these tools can help enhance the accuracy $^{21}$, the REBUS procedure done without these tools reduce the cost of procedure, as well as the risk of radiation exposure ${ }^{11-13}$. Moreover, Zhang et al's study ${ }^{22}$ suggested the diagnostic yield with R-EBUS with distance-measurement is not inferior to the yield with R-EBUS with GS. In studies with R-EBUS procedure with distance-measurement method, the reported diagnostic accuracy was $77 \%-87 \%^{11,12,23}$ and we achieved an $80 \%$ diagnostic yield. Although R-EBUS-guided TBLB showed comparable accuracy to transthoracic needle biopsy ${ }^{24}$, the relatively high rate of false-negatives resulted in low negative predictive values (44\%-46\%), including in our study ${ }^{25}$. Bronchial brushing we did not use in this study could be good additional tool to improve the diagnostic rate ${ }^{26}$. To lower the rate of falsenegative results and enhance the accuracy, further studies of various methods using R-EBUS are warranted.

In addition to R-EBUS, promising techniques for interventional bronchoscopy of peripheral lung lesions include $\mathrm{ENB}^{27}$ and $\mathrm{VB}^{7,28}$. The reported diagnostic performance was $74 \%$ with $\mathrm{ENB}^{4}$ and about $80 \%$ with $\mathrm{VB}^{29,30}$ and the combination of these modalities achieved success rate of $80 \%-81 \%$ (R-EBUS and $\mathrm{VB})^{5,31}$ and $63 \%-73 \%$ (R-EBUS and ENB) ${ }^{32,33}$. There was no clear indication for these tools, thus the comparisons and combinations to establish proper use are still required.

Various predictors associated with an accurate diagnosis have been suggested, including a middle lobar location of the lesion $^{16,18}$ and the bronchus sign on $\mathrm{CT}^{15,18}$. Other studies have emphasized larger sized ${ }^{6,18,20,21,25,26}$, and solid lesions, rather than ground-glass opacity ${ }^{18}$, and malignant rather than benign lesions ${ }^{9,10,25}$. Consistent with previous studies, we found that probe position within the lesion on ultrasonography predicted the accuracy of diagnosis ${ }^{6,14,21,25}$. In addition, this study demon- 
Table 3. Factors for accurate diagnosis with R-EBUS-guided biopsy in patients with malignancy (n=143)

\begin{tabular}{|c|c|c|c|c|c|c|}
\hline & \multirow{2}{*}{$\begin{array}{l}\text { True-positive } \\
\qquad(n=109)\end{array}$} & \multirow{2}{*}{$\begin{array}{l}\text { False-negative } \\
\qquad(n=34)\end{array}$} & \multicolumn{2}{|c|}{ Univariate analysis } & \multicolumn{2}{|c|}{ Multivariable analysis } \\
\hline & & & OR (95\% CI) & p-value & aOR (95\% CI) & p-value \\
\hline Male sex & $53(49)$ & $18(53)$ & $0.841(0.389-1.819)$ & 0.660 & & \\
\hline Size, $\mathrm{mm}$ & & & & 0.047 & & 0.077 \\
\hline$\leq 30$ & $49(45)$ & $22(65)$ & 1.000 & & 1.000 & \\
\hline$>30$ & $60(55)$ & $12(35)$ & $2.245(1.010-4.987)$ & & $2.193(0.919-5.234)$ & \\
\hline Histology & & & & 0.291 & & \\
\hline Others & $17(30)$ & $8(24)$ & 1.000 & & & \\
\hline Adenocarcinoma & $92(70)$ & $26(76)$ & $1.665(0.646-4.290)$ & & & \\
\hline Characteristics & & & & 0.318 & & \\
\hline Non-solid & $23(21)$ & $10(29)$ & 1.000 & & & \\
\hline Solid & $86(79)$ & $24(71)$ & $1.558(0.653-3.717)$ & & & \\
\hline Location & & & & 0.246 & & \\
\hline Upper lobes & $44(40)$ & $19(56)$ & 1.000 & & & \\
\hline Middle lobes* & $23(21)$ & $4(12)$ & $2.483(0.755-8.164)$ & & & \\
\hline Lower lobes & $42(39)$ & $11(32)$ & $1.649(0.702-3.875)$ & & & \\
\hline Lung zone on CT scan & & & & 0.035 & & 0.023 \\
\hline Central, one-third & $8(7)$ & $7(21)$ & 1.000 & & 1.000 & \\
\hline Peripheral, two-third & $101(93)$ & $27(79)$ & $3.273(1.090-9.830)$ & & $3.925(1.203-12.811)$ & \\
\hline Bronchus sign on CT scan & & & & 0.077 & & \\
\hline Adjacent or Invisible & $42(39)$ & $19(56)$ & 1.000 & & & \\
\hline Central & $67(61)$ & $15(44)$ & $2.021(0.927-4.404)$ & & & \\
\hline Bronchus sign on US & & & & 0.005 & & 0.035 \\
\hline Adjacent & $33(31)$ & $20(59)$ & 1.000 & & 1.000 & \\
\hline Within & $73(69)$ & $14(41)$ & $3.160(1.424-7.013)$ & & $2.435(1.064-5.572)$ & \\
\hline
\end{tabular}

Values are presented as number (\%) or median (interquartile range).

*Middle lobes included right middle lobe and left upper lobe lingular division.

R-EBUS: radial-probe endobronchial ultrasound; OR: odds ratio; CI: confidence interval; aOR: adjusted odds ratio; CT: computed tomography; US: ultrasonography.

Table 4. Molecular and genetic evaluation in malignancy with R-EBUS-guided biopsy

\begin{tabular}{|lcccc|}
\hline Molecular/genetic testing & $\begin{array}{c}\text { EGFR in malignancy } \\
(\mathbf{n}=\mathbf{1 0 9})\end{array}$ & $\begin{array}{c}\text { EGFR in ADC } \\
(\mathbf{n}=\mathbf{9 2})\end{array}$ & $\begin{array}{c}\text { ALK IHC in ADC } \\
(\mathbf{n}=\mathbf{9 2})\end{array}$ & $\begin{array}{c}\text { PD-L1 IHC in ADC } \\
(\mathbf{n}=\mathbf{9 2})\end{array}$ \\
\hline Attempted & 64 & 58 & 60 & 17 \\
Successful & 63 & 57 & 60 & 16 \\
Inadequate specimen & 1 & 1 & 0 & 1 \\
Not attempted & 45 & 34 & 32 & 75 \\
\hline
\end{tabular}

Values are presented as number of patients.

R-EBUS: radial-probe endobronchial ultrasound; EGFR: epidermal growth factor receptor; ADC: adenocarcinoma; ALK: anaplastic lymphoma kinase; IHC: immunohistochemistry; PD-L1: programmed death-ligand 1.

strated a peripheral location was also an important factor. The most like reason was that it was difficult to maintain positioning of the bronchoscope in the target bronchus for a central le- sion without a GS in contrast to the case of a peripheral lesion; the radial probe and a 4-mm thin bronchoscope could access the target bronchus more closely without a GS. Placing an 
emphasis on these factors could be helpful and further studies to identify the patients most likely to benefit from R-EBUS are needed.

Regarding the feasibility of molecular and genetic testing, the reported likelihood of obtaining sufficient specimens for EBUS-guided trans-bronchial needle aspiration was high ${ }^{34}$. In $\mathrm{ENB}$, adequate tissue was obtained in $80 \%$ of the cases that in which molecular genetic testing was attempted ${ }^{35}$. However, there is limited information on the efficacy of genetic testing using samples obtained by R-EBUS. Two studies reported genotyping analyses, one using excess brushing samples, which had a 95\% success rate $\mathrm{e}^{36}$ and another using a $1.5-\mathrm{mm}$ microbiopsy forceps, which had a $67 \%-89 \%$ success rate in non-squamous cell non-small cell lung cancer ${ }^{37}$. We obtained a sufficient tissue sample in almost all cases (94\%-100\%) for studies including EGFR, ALK IHC, and PD-L1 IHC, perhaps because the procedure without a GS allowed for optimized tissue sampling through use of bigger $(1.8 \mathrm{~mm})$ biopsy forceps.

This study had several limitations. First, it was conducted only by a single experienced physician in a center retrospectively, so a potential selection bias could exist and therefore, diagnostic rate might be overestimated. Second, the length of procedure time and the number of biopsy were not analyzed because they were not measured in this study. Finally, molecular and genetic testing were not performed in all cases. However, these analyses were performed in a considerable proportion of the patients and relatively high efficacy was achieved.

In conclusion, R-EBUS-guided biopsy without both a GS and fluoroscopy is useful for tissue diagnosis. A peripheral location and the probe position during the procedure were important for an accurate diagnosis. Moreover, molecular and genetic testing using samples obtained by R-EBUS were highly satisfactory. Further studies should identify the patients who would most benefit from R-EBUS.

\section{Authors' Contributions}

Conceptualization: Moon SM, Lee K. Methodology: Moon SM, Choe J, Lee K. Formal analysis: Moon SM, Choe J, Lee K. Data curation: Moon SM, Choe J, Lee K. Validation: Moon SM, Choe J, Lee K. Investigation: Moon SM, Choe J, Lee K. Writing - original draft: Moon SM. Writing - review \& editing: Choe J, Jeong BH, Um SW, Kim H, Kwon OJ, Lee K. Approval of final manuscript: all authors.

\section{Conflicts of Interest}

No potential conflict of interest relevant to this article was reported.

\section{Funding}

No funding to declare.

\section{References}

1. Politi K, Herbst RS. Lung cancer in the era of precision medicine. Clin Cancer Res 2015;21:2213-20.

2. Folch E, Costa DB, Wright J, VanderLaan PA. Lung cancer diagnosis and staging in the minimally invasive age with increasing demands for tissue analysis. Transl Lung Cancer Res 2015;4:392-403.

3. Baaklini WA, Reinoso MA, Gorin AB, Sharafkaneh A, Manian P. Diagnostic yield of fiberoptic bronchoscopy in evaluating solitary pulmonary nodules. Chest 2000;117:1049-54.

4. Gildea TR, Mazzone PJ, Karnak D, Meziane M, Mehta AC. Electromagnetic navigation diagnostic bronchoscopy: a prospective study. Am J Respir Crit Care Med 2006;174:982-9.

5. Ishida T, Asano F, Yamazaki K, Shinagawa N, Oizumi S, Moriya $\mathrm{H}$, et al. Virtual bronchoscopic navigation combined with endobronchial ultrasound to diagnose small peripheral pulmonary lesions: a randomised trial. Thorax 2011;66:10727 .

6. Chen A, Chenna P, Loiselle A, Massoni J, Mayse M, Misselhorn D. Radial probe endobronchial ultrasound for peripheral pulmonary lesions: a 5-year institutional experience. Ann Am Thorac Soc 2014;11:578-82.

7. Chenna P, Chen AC. Radial probe endobronchial ultrasound and novel navigation biopsy techniques. Semin Respir Crit Care Med 2014;35:645-54

8. Anantham D, Koh MS, Ernst A. Endobronchial ultrasound Respir Med 2009;103:1406-14.

9. Ali MS, Trick W, Mba BI, Mohananey D, Sethi J, Musani AI Radial endobronchial ultrasound for the diagnosis of peripheral pulmonary lesions: a systematic review and metaanalysis. Respirology 2017;22:443-53.

10. Steinfort DP, Khor YH, Manser RL, Irving LB. Radial probe endobronchial ultrasound for the diagnosis of peripheral lung cancer: systematic review and meta-analysis. Eur Respir J 2011;37:902-10.

11. Fuso L, Varone F, Magnini D, Baldi F, Rindi G, Pagliari G, et al. Role of ultrasound-guided transbronchial biopsy in the diagnosis of peripheral pulmonary lesions. Lung Cancer 2013;81:60-4.

12. Evison M, Crosbie PA, Morris J, Martin J, Barber PV, Booton R. Can computed tomography characteristics predict outcomes in patients undergoing radial endobronchial ultrasoundguided biopsy of peripheral lung lesions? J Thorac Oncol 2014;9:1393-7.

13. Wang Y, Mei Q, Ai YQ, Li RQ, Chang L, Li YF, et al. Identification of lung cancer oncogenes based on the mRNA expression and single nucleotide polymorphism profile data. Neo- 
plasma 2015;62:966-73.

14. Yamada N, Yamazaki K, Kurimoto N, Asahina H, Kikuchi E, Shinagawa N, et al. Factors related to diagnostic yield of transbronchial biopsy using endobronchial ultrasonography with a guide sheath in small peripheral pulmonary lesions. Chest 2007;132:603-8.

15. Minezawa T, Okamura T, Yatsuya H, Yamamoto N, Morikawa $\mathrm{S}$, Yamaguchi T, et al. Bronchus sign on thin-section computed tomography is a powerful predictive factor for successful transbronchial biopsy using endobronchial ultrasound with a guide sheath for small peripheral lung lesions: a retrospective observational study. BMC Med Imaging 2015;15:21.

16. Eberhardt R, Ernst A, Herth FJ. Ultrasound-guided transbronchial biopsy of solitary pulmonary nodules less than $20 \mathrm{~mm}$. Eur Respir J 2009;34:1284-7.

17. Izumo T, Sasada S, Chavez C, Matsumoto Y, Hayama M, Tsuchida T. The diagnostic value of histology and cytology samples during endobronchial ultrasound with a guide sheath. Jpn J Clin Oncol 2015;45:362-6.

18. Yoshikawa M, Sukoh N, Yamazaki K, Kanazawa K, Fukumoto S, Harada M, et al. Diagnostic value of endobronchial ultrasonography with a guide sheath for peripheral pulmonary lesions without X-ray fluoroscopy. Chest 2007;131:1788-93.

19. Chan A, Devanand A, Low SY, Koh MS. Radial endobronchial ultrasound in diagnosing peripheral lung lesions in a high tuberculosis setting. BMC Pulm Med 2015;15:90.

20. Casutt A, Prella M, Beigelman-Aubry C, Fitting JW, Nicod L, Koutsokera A, et al. Fluoroscopic-guided radial endobronchial ultrasound without guide sheath for peripheral pulmonary lesions: a safe and efficient combination. Arch Bronconeumol 2015;51:338-43.

21. Haidong H, Yunye N, Wei Z, Zarogoulidis P, HohenforstSchmidt W, Man YG, et al. Multiple guided technologies based on radial probe endobronchial ultrasound for the diagnosis of solitary peripheral pulmonary lesions: a single-center study. J Cancer 2017;8:3514-21.

22. Zhang SJ, Zhang M, Zhou J, Zhang QD, Xu QQ, Xu X. Comparison of radial endobronchial ultrasound with a guide sheath and with distance by thin bronchoscopy for the diagnosis of peripheral pulmonary lesions: a prospective randomized crossover trial. J Thorac Dis 2016;8:3112-8.

23. Zhang SJ, Zhang M, Zhou J, Zhang QD, Xu QQ, Xu X. Radial endobronchial ultrasonography with distance measurement through a thin bronchoscope for the diagnosis of malignant peripheral pulmonary lesions. Transl Lung Cancer Res 2018;7:80-7.

24. Steinfort DP, Vincent J, Heinze S, Antippa P, Irving LB. Comparative effectiveness of radial probe endobronchial ultrasound versus CT-guided needle biopsy for evaluation of peripheral pulmonary lesions: a randomized pragmatic trial. Respir Med 2011;105:1704-11.

25. Xu CH, Yuan Q, Yu LK, Wang W, Lin Y. Endobronchial ultrasound transbronchial biopsy with guide-sheath for the diagnosis of solitary pulmonary nodules. Oncotarget 2017;8:58272-7.

26. Kuo CH, Lin SM, Lee KY, Chung FT, Lo YL, Hsiung TC, et al. Endobronchial ultrasound-guided transbronchial biopsy and brushing: a comparative evaluation for the diagnosis of peripheral pulmonary lesions. Eur J Cardiothorac Surg 2014;45:894-8.

27. Gex G, Pralong JA, Combescure C, Seijo L, Rochat T, Soccal PM. Diagnostic yield and safety of electromagnetic navigation bronchoscopy for lung nodules: a systematic review and meta-analysis. Respiration 2014;87:165-76.

28. Asano F, Eberhardt R, Herth FJ. Virtual bronchoscopic navigation for peripheral pulmonary lesions. Respiration 2014;88:430-40.

29. Tachihara M, Ishida T, Kanazawa K, Sugawara A, Watanabe K, Uekita K, et al. A virtual bronchoscopic navigation system under X-ray fluoroscopy for transbronchial diagnosis of small peripheral pulmonary lesions. Lung Cancer 2007;57:322-7.

30. Iwano S, Imaizumi K, Okada T, Hasegawa Y, Naganawa S. Virtual bronchoscopy-guided transbronchial biopsy for aiding the diagnosis of peripheral lung cancer. Eur J Radiol 2011;79:155-9.

31. Asano F, Shinagawa N, Ishida T, Shindoh J, Anzai M, Tsuzuku A, et al. Virtual bronchoscopic navigation combined with ultrathin bronchoscopy. A randomized clinical trial. Am J Respir Crit Care Med 2013;188:327-33.

32. Ozgul G, Cetinkaya E, Ozgul MA, Abul Y, Gencoglu A, Kamiloglu E, et al. Efficacy and safety of electromagnetic navigation bronchoscopy with or without radial endobronchial ultrasound for peripheral lung lesions. Endosc Ultrasound 2016;5:189-95.

33. Georgiou HD, Taverner J, Irving LB, Steinfort DP. Safety and efficacy of radial EBUS for the investigation of peripheral pulmonary lesions in patients with advanced COPD. J Bronchology Interv Pulmonol 2016;23:192-8.

34. Jurado J, Saqi A, Maxfield R, Newmark A, Lavelle M, Bacchetta $\mathrm{M}$, et al. The efficacy of EBUS-guided transbronchial needle aspiration for molecular testing in lung adenocarcinoma. Ann Thorac Surg 2013;96:1196-202.

35. Khandhar SJ, Bowling MR, Flandes J, Gildea TR, Hood KL, Krimsky WS, et al. Electromagnetic navigation bronchoscopy to access lung lesions in 1,000 subjects: first results of the prospective, multicenter NAVIGATE study. BMC Pulm Med 2017;17:59.

36. Tsai TH, Yang CY, Ho CC, Liao WY, Jan IS, Chen KY, et al. Multi-gene analyses from waste brushing specimens for patients with peripheral lung cancer receiving EBUS-assisted bronchoscopy. Lung Cancer 2013;82:420-5.

37. Guisier F, Salaun M, Lachkar S, Lamy A, Piton N, Obstoy B, et al. Molecular analysis of peripheral non-squamous nonsmall cell lung cancer sampled by radial EBUS. Respirology 2016;21:718-26. 